\title{
Tropical Medicine in the Horse Latitudes
}

\author{
Peter Hotez
}

Published online: 7 January 2014

(C) Springer International Publishing AG 2014

\begin{abstract}
Some of the world's highest rates of neglected tropical diseases (NTDs) now occur among impoverished populations who live in the midst of wealth, especially in middle- and high-income countries. An illustrative example is the poor who live in nations between the 30th and 35th parallels, also known as the "horse latitudes." Focusing on the northern horse latitudes, emerging information reveals that the neglected tropical diseases are widespread in the Middle East and North Africa, Afghanistan, Pakistan, North India, Nepal, China, and in Texas and the southern United States, particularly vector-borne tropical infections such as dengue fever and other arbovirus infections, leishmaniasis, as well as selected helminthiases. In Texas a new tropical medicine school has been established to combat such neglected tropical diseases, but worldwide there is an urgent need to generate a public policy for these conditions, as they emerge primarily among the poor and disenfranchised.
\end{abstract}

Keywords Neglected tropical diseases (NTDs) · Horse latitudes $\cdot$ Parkistan $\cdot$ India $\cdot$ Nepal $\cdot$ China $\cdot$ Texas $\cdot$ Dengue $\cdot$ Toxocariasis $\cdot$ Chagas $\cdot$ West Nile $\cdot$ Cysticercosis $\cdot$ Leishmaniasis $\cdot$ Murine fever $\cdot$ Typhoid

P. Hotez $(\bowtie)$

Texas Children's Hospital Endowed Chair of Tropical Pediatrics, Baylor College of Medicine, Houston, TX 77030, USA

e-mail: hotez@bcm.edu

P. Hotez

Pediatrics and Molecular Virology and Microbiology, Baylor College of Medicine, Houston, TX 77030, USA

P. Hotez

National School of Tropical Medicine, Baylor College of Medicine, Houston, TX 77030, USA

P. Hotez

Sabin Vaccine Institute and Texas Children's Hospital Center for Vaccine Development, Baylor College of Medicine, Houston, TX 77030, USA
Our modern framework of tropical medicine is heavily focused on the neglected tropical diseases (NTDs), a concept that emerged in the new millennium following the launch of the Millennium Development Goals and Tony Blair's Commission for Africa [1]. Together with key policy papers on the concept of integrating NTD control or elimination by simultaneously targeting seven major NTDs (ascariasis, trichuriasis, hookworm infection, schistosomiasis, lymphatic filariasis, onchocerciasis, and trachoma) [2] and their potential links with falciparum malaria and HIV/AIDS [3], the initial emphasis centered on these diseases as they relate to the health and economic development of sub-Saharan Africa.

A more thorough analysis, however, reveals that while subSaharan Africa accounts for most or all of the disease burden of several important NTDs including schistosomiasis, onchocerciasis, and human African sleeping sickness [4], the overall highest disease burden of the 17 NTDs - as they are currently defined by the World Health Organization (WHO) [5] - actually occurs outside of this region. Indeed, one recent analysis finds that the largest number of cases of NTDs with high disease burdens - diseases such as lymphatic filariasis, foodborne trematodiases, Chagas disease, and dengue fever - can be found among the poor living in group of 20 (G20 countries) such as India, Indonesia, China, Brazil, Saudi Arabia, and to some extent, even the southern part of the United States [6]. The term "blue marble health" has been coined to suggest that the old framework of global health emphasizing developing versus developed countries may no longer hold $[1,6]$. Instead, given that poverty is the overriding predictor of where NTDs can be found, it is the poor living in more developed countries that account for many of the world's NTDs $[1,6]$.

Along those lines, it is worth taking a snapshot of our planet along a band of subtropical latitudes that run between 30 and 35 degrees, also known as the "horse latitudes" (Fig. 1) [7]. Comprised mostly of middle-income and high-income areas that include the southern United States, the Middle East 


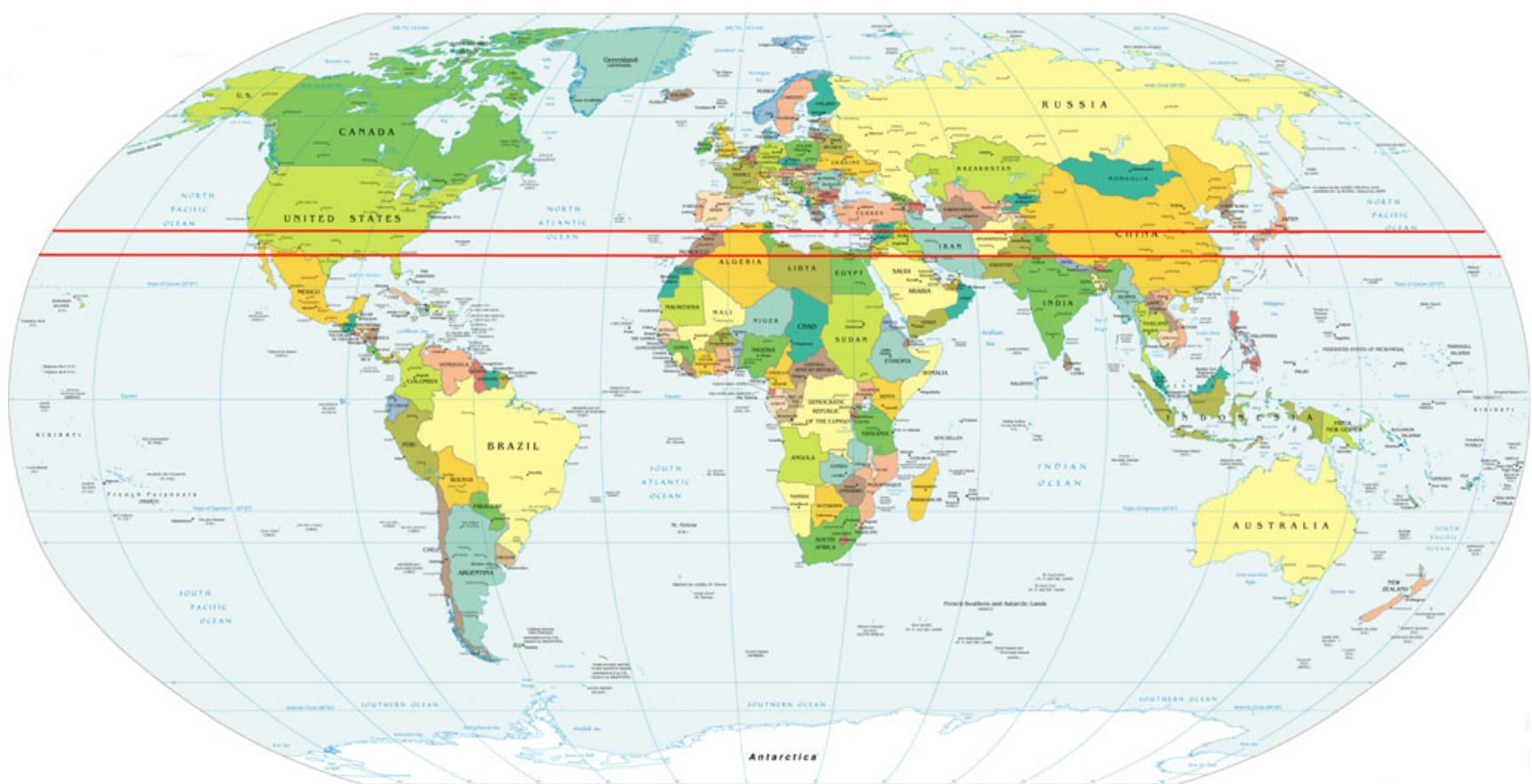

Fig. 1 The 30th and 35th parallels north, borders of the northern "horse latitudes." Map adapted from University of Texas Perry Castañeda Library Map Collection. Courtesy of the University of Texas Libraries, The University of Texas at Austin. http://www.lib.utexas.edu/maps/

and North Africa, Afghanistan, Pakistan, North India, Nepal, and the major cities of "China's furnace", i.e., Chongqing, Wuhan, Nanjing, Changsha, and Nanchang (referring to their hot and humid summers), there is increasing evidence for the northern horse latitudes emerging as a new hotbed of tropical diseases.

In the Middle East and North Africa at least one component of tropical diseases is related to conflict and political instability $[8,9]$. Cutaneous leishmaniasis, also known as "Aleppo ulcer," has become widespread in Syria and refugee camps in Turkey and Lebanon. Canine rabies and even polio have re-emerged in Syria. Dengue fever is now widespread in Egypt, but it is also present in Saudi Arabia, Syria, and Yemen [10]. Several viral infections, including MERS coronavirus, Alkhurma hemorrhagic virus, and Rift Valley fever have also recently emerged [8]. According to the WHO, the Middle East and North Africa region also has one of the worst track records for deworming its population such that soil-transmitted helminth infections are still common, especially in the poorest areas [11].

India, and to some extent Pakistan and Nepal, fare no better and are also severely threatened by vector-borne NTDs [12]. India now has the world's largest number of cases of dengue fever [10]. The disease has gained national attention after it killed a major Bollywood director and affected a major film star [13]. Malaria is still a leading killer in India [14], as is visceral leishmaniasis [15]. India is also under severe threat from Chikungunya and Japanese encephalitis, and it has some of the largest numbers of cases of soil-transmitted helminth infections and populations requiring treatment of lymphatic filariasis $[11,12]$. Further east, the poorest people in China exhibit the highest infection rates from food-borne trematodiases [16], and they still suffer from soil-transmitted helminth infections and schistosomiasis [17], as well as a high incidence of dengue fever [10].

Despite the fact that the United States has the world's largest economy, it also has pockets of intense poverty, especially in the southern United States [18]. In 2011 a new National School of Tropical Medicine was established at Houston's Baylor College of Medicine in partnership with Texas Children's Hospital. Establishing such a school in the horse latitudes affords a unique opportunity to conduct studies on NTDs in an area not previously thought of as endemic for these conditions [19]. It has since become apparent that dengue fever re-emerged in Houston beginning in 2003 [20], and in many areas of Texas, West Nile virus infection can produce a chronic renal syndrome that in some cases leads to kidney failure [21]. Autochthonous cases of Chagas disease are probably far more common than previously believed [22], as are cysticercosis, cutaneous leishmaniasis, and murine typhus [23]. In most cases these NTDs are disproportionately affecting the poor and the homeless. In partnership with the Harris Health System, a new tropical medicine clinic has opened and now sees (mostly indigent) patients with NTDs weekly.

One common theme across the horse latitudes is that many of its NTDs are hidden from view, in part because the poor often go unseen. People living in extreme poverty often do not have access to adequate health care and conducting surveillance studies among such vulnerable populations is seldom prioritized. For example, in the case of Texas and neighboring regions in the southern United States, there is an extreme dearth 
of information and data on the NTDs, which itself becomes a barrier to marshalling resources for combating these infections. We face a true "chicken and egg" problem: no data and no resources, but without resources we cannot generate data.

To date, efforts to generate federal legislation to address NTDs in the United States or North America have not been productive, and it is unclear whether the global community is sufficiently prioritizing the Middle East and North Africa, India, and China in terms of their widespread NTDs. Yet given that emerging information continues to reinforce the concepts of blue marble health - NTDs are at their zenith in the poor who live among the wealthy - this framework will continue to be an important global health theme in the coming decade.

\section{Compliance with Ethics Guidelines}

Conflict of Interest The author is the patentholder and principal investigator on vaccines in development against hookworm, schistosomiasis, and Chagas disease.

Human and Animal Rights and Informed Consent This article does not contain any studies with human or animal subjects performed by any of the authors.

\section{References}

1. Hotez PJ. NTDs V.2.0: "Blue marble health" - neglected tropical disease control and elimination in a shifting health policy landscape. PLOS Negl Trop Dis 2014; 8: in press.

2. Molyneux DH, Hotez PJ, Fenwick A. "Rapid-impact interventions": how a policy of integrated control for Africa's neglected tropical diseases could benefit the poor. PLoS Med. 2005;2:e336.

3. Hotez PJ, Molyneux DH, Fenwick A, Ottesen E, Ehrlich Sachs S, Sachs JD. Incorporating a rapid-impact package for neglected tropical diseases with programs for HIV/AIDS, tuberculosis, and malaria. PLoS Med. 2006;3:e102.

4. Hotez PJ, Kamath A. Neglected tropical diseases in sub-saharan Africa: review of their prevalence, distribution, and disease burden. PLoS Negl Trop Dis. 2009;3:e412.

5. http://www.who.int/neglected diseases/diseases, accessed October 27, 2013.

6. Hotez P. The disease next door. Foreign Policy March 25, 2013, http://www.foreignpolicy.com/articles/2013/03/25/the_disease_ next_door, accessed October 27, 2013.
7. http://en.wikipedia.org/wiki/Horse_latidudes, accessed October 27, 2013.

8. Hotez PJ, Savioli L, Fenwick A. Neglected tropical diseases of the Middle East and North Africa: review of their prevalence, distribution, and opportunities for control. PLoS Negl Trop Dis. 2012;6: e1475.

9. Hotez P. Arab revolutions: ignoring a potential catastrophe. Al Jazeera America August 16, 2013, http://www.aljazeera.com/ indepth/opinion/2013/08/2013815123611973409.html, accessed October 27, 2013.

10. Bhatt S, Gething PW, Brady OJ, Messina JP, Farlow AW, et al. The global distribution and burden of dengue. Nature. 2013;496: 504-7.

11. World Health Organization. Soil-transmitted helminthiases: number of children treated in 2010. Wkly Epidemiol Rec. 2012;87:225-32.

12. Hotez P. Why India and Pakistan must be united on health care. Global Post October 20, 2013. http://www.globalpost.com/ dispatches/globalpost-blogs/commentary/india-pakistan-centercombat-killer-tropical-diseases, accessed October 27, 2013.

13. Khazan O. In India, dengue panic after Bollywood movie mogul Yash Chopra's death. The Washingotn Post October 30, 2012; http:// www.washingtonpost.com/blogsworldviews/wp/2012/10/30/ dengue-fever-india, accessed October 27, 2013.

14. Hay SI, Gething PW, Snow RW. India's invisible malaria burden. Lancet. 2010;376:1716-7.

15. Alvar J, Velez ID, Bern C, Herrero M, Desjeux P, Cano J, et al. WHO Leishmaniasis Control Team. PLoS ONE. 2012;7:e35671.

16. Furst T, Keiser J, Utzinger J. Global burden of human food-borne trematodiases: a systematic review and meta-analysis. Lancet Infect Dis. 2012;12:210-21.

17. Hotez PJ. Engaging a rising China through neglected tropical diseases. PLoS Negl Trop Dis. 2012;6:e1599.

18. Hotez PJ. Fighting neglected tropical diseases in the southern United States. BMJ. 2012;345:e6112.

19. Hotez P. A national school of tropical medicine and neglected infections of poverty for North America. PLoS Negl Trop Dis. 2010;4: e735.

20. Murray IKO Rodriguez LF, Herrington E, Kharat V, Vasilakis N, et al. Identification of dengue fever cases in Houston, Texas, with evidence of autochthonous transmission between 2003 and 2005. Vector Borne Zoonotic Dis 2013 [Epub ahead of print].

21. Nolan MS, Podoll AS, Hause AM, Akers KM, Finkel KW, Murray KO. Prevalence of chronic kidney disease and progression of disease over time among patients enrolled in the Houston West Nile virus cohort. PLoS One. 2012;7:e40374.

22. Hotez PJ, Dumonteil E, Betancourt Cravioto M, Bottazzi ME, et al. An unfolding tragedy of Chagas disease in North America. PLoS Negl Trop Dis. 2013;7:e2300.

23. Andrus J, Bottazzi ME, Chow J, Goraleski KA, Fisher-Hoch SP, et al. Ears of the armadillo: global health research and neglected diseases in Texas. PLoS Negl Trop Dis. 2013;7:e2021. 